\title{
BALAGUER AL DESNUDO EN EL CUENTO EL OIDOR, DE EFRAÍM CASTILLO
}

\section{Balaguer Naked in the Story The Hearer, By Efraín Castillo}

\section{Patricio García Polanco}

Profesor de la Universidad Abierta para Adultos. Santiago de los Caballeros. República Dominicana

ORCID: 0000-0001-6787-5803, Correo-e: patriciogarcia6@gmail.com

Recibido: 27/7/2020 • Aprobado: 19/9/2020

Cómo citar: García Polanco, P. (2020). Balaguer al desnudo en el cuento El oidor, de Efraím Castillo. Ciencia y Sociedad, 45(4), 135-145. Doi: https://doi.org/10.22206/cys.2020.v45i4.pp135-145

\section{Resumen}

El presente trabajo constituye un estudio del cuento $E l$ oidor de Efraím Castillo, en el que, a través del análisis crítico y la revisión bibliográfica, se pretende establecer la estrecha relación que hay entre el personaje literario que lo protagoniza (el oidor) y el personaje histórico que lo inspiró (Joaquín Balaguer). Recurriendo a datos históricos, así como a otros textos literarios y críticos, se compara la personalidad del ente del relato con el ser concreto que vivió y ejerció la actividad política, y se subraya el acierto del autor al recrear rasgos típicos de la personalidad del caudillo. El trabajo destaca que tanto en la realidad social como en la ficción de Castillo el personaje sobresale por uno de sus rasgos más característicos: la no aceptación de la disidencia, de ahí que la intolerancia constituya uno de los comportamientos típicos en el accionar del oidor (personaje ficcional) y de Joaquín Balaguer (personaje real). Al final, como resultado de esas comparaciones, se concluye que, efectivamente, hay un vínculo directo, identificable, entre el personaje textual, el oidor, y la persona real que lo inspira, el caudillo político y escritor Joaquín Balaguer.

Palabras clave: cuento; literatura dominicana; Joaquín Balaguer; Efraím Castillo; política; autoritarismo.

\section{Abstract}

This work constitutes a study of the story El oidor by Efraím Castillo, in which, through critical analysis and bibliographic review, it is intended to establish the close relationship between the literary character that stars in it (el oidor) and the historical character that inspired him (Joaquín Balaguer). Using historical data, as well as other literary and critical texts, the personality of the entity in the story is compared with the concrete being who lived and exercised political activity, and the author's success in recreating typical features of the leader's personality is underlined. The work highlights that both in social reality and in Castillo's fiction the character stands out for one of his most characteristic features: the non-acceptance of dissent, hence intolerance constitutes one of the typical behaviors in the actions of el oidor (fictional character) and Joaquín Balaguer (real character). In the end, as result of these comparisons, it is concluded that, indeed, there is a direct, identifiable link between the textual character, el oidor, and the real person who inspires him, the political leader and writer Joaquín Balaguer.

Keywords: short story; Dominican literatura; Joaquín Balaguer; Efraím Castillo; politics; authoritarianism. 


\section{Introducción}

La controversial figura de Joaquín Balaguer es el eje central del cuento El oidor, de Efraím Castillo. Aunque el personaje no aparece identificado, los datos que aporta el narrador, conforme va desenvolviéndose la trama, permiten que el lector lo advierta, inclusive desde los primeros párrafos. El que la identidad de la figura no fuera expuesta es entendible, si tenemos en cuenta que el Dr. Balaguer ocupaba la Presidencia de la República Dominicana para 1988, fecha en que el cuento fue escrito $^{1}$. Una razón justificable para que Castillo presentara al personaje omitiendo sus señas de identidad $^{2}$. Se entiende, además, que para los fines literarios correspondientes convenía más que el lector fuera adivinando a medida que avanzara en su lectura quién era el extraño personaje. Levantar el velo desde el principio le habría conferido un carácter más próximo al libelo que a la ficción literaria.

El argumento del cuento es este: el personaje principal (identificado como el oidor), anciano octogenario y ciego, que ejerce la Presidencia del país, es asistido por Jaime Larancuent, quien realizaba la función de leedor personal. Este leedor acude en las primeras horas de la mañana a la habitación

\footnotetext{
${ }^{1}$ Como es habitual en muchos escritores colocar al final del texto la fecha en que concluyen su redacción, Castillo cierra su cuento con esta línea: octubre de 1988. Desconocemos la fecha en que fue publicado y en cuál libro fue incluido. La versión que hemos escogido para el presente artículo corresponde a la Antología del Cuento Dominicano, de Diógenes Céspedes, publicado en el año 1996.

${ }^{2}$ La desaparición del profesor universitario Narciso González -Narcisazo- el 26 de mayo de 1994, después de haber hecho duras críticas al presidente Joaquín Balaguer, permite apreciar lo embarazoso que podría llegar a ser el abordaje crítico de la figura presidencial. Y no solo por los medios directos de la prensa, sino a través de procedimientos estéticos, como fue el caso de Viriato Sención cuatro años después de la escritura de El oidor (es decir, en 1992) y dos años antes del secuestro y desaparición de dicho profesor. La intolerancia y la violencia eran comportamientos consustanciales a los gobiernos balagueristas.
}

personal del anciano ${ }^{3}$ para leerle los diarios del día, también cartas y documentos oficiales. Uno de esos días, el anciano, interrumpe la lectura que le hacía el señor Larancuent y le pide que le abra la ventana de la recámara, disposición que el empleado cumple de inmediato. Entonces el oidor le solicita al leedor que le describa lo que ve a través de la ventana. Este le describe algunos elementos del paisaje natural y cultural que hay en las proximidades, así como figuras del paisaje humano que se desplazan por los alrededores. Pero el leedor comete la imprudencia de comentar que ve personas cabizbajas transitando por la calle. Esto genera una reacción del anciano, quien se muestra interesado en saber por qué se notan de tan mal ánimo los transeúntes. Después de mucha insistencia por parte del oidor, al no poder el leedor esquivar la situación, afirma que la gente está inconforme, y cita como justificación la situación económica. La escena adquiere su mayor tensión cuando el locutor advierte al mandatario que sus funcionarios le engañan, que no le dicen la verdad sobre lo que está pasando en el país. Al concluir la sesión de lectura de ese día, el anciano, disgustado, pero sin expresarlo de manera concreta, despide a Larancuent, y cuando este se ha marchado le ordena al general que suspendan los servicios del leedor.

\section{Entre el Balaguer histórico y el ficcional. Un retrato físico y moral del anciano caudillo de Navarrete}

La coincidencia entre el personaje del oidor y el presidente Balaguer es bastante evidente. Veamos en detalle los rasgos que caracterizan al personaje de ficción en cuestión y al sujeto real y concreto del que procede. Desde la primera escena nos encontramos con un general que aparece en el antedespacho del anciano. Un poco más adelante, seguramente el lector del cuento intuirá que se

\footnotetext{
${ }^{3}$ La historia tiene como escenario la alcoba del Presidente y no el despacho presidencial. Esto es así porque la sesión de lectura se realizaba a partir de las 7:30 de la mañana, antes de que el mandatario partiera a la sede del gobierno en el Palacio Nacional.
} 
trata de una recreación ficcional del general Luis Pérez Bello, asistente del Dr. Balaguer durante los últimos años en que ejerció la Presidencia y luego de este haber cesado como mandatario y pasar a su involuntario retiro de la avenida Máximo Gómez.

El oidor y presidente de la república es un letrado, con limitaciones físicas propias de la avanzada edad, pero — sobre todo — debido a la ceguera que padece. Esa última condición es la razón por la que se ve en la necesidad de contratar leedores para que le mantengan al tanto de las informaciones que circulan en la prensa, además de las correspondencias y de otros documentos de interés personal y público. Y más allá de esas rutinarias lecturas de documentos de índole práctica, también estaba la necesidad de seguir disfrutando de las creaciones literarias, asunto muy del interés particular del gobernante.

El anciano tiene rango académico de doctor, o al menos es llamado por ese título, tal como ocurría con el doctor Balaguer. La descripción del personaje por parte del narrador no puede ser más coincidente. Al hablar de su ceguera, expresa: "aquellos ojos octogenarios, roídos por un millón de lecturas, hacinados en las paredes de embajadas y recovecos palaciegos" (Castillo, 1996, p. 203). Como es bien sabido, el Dr. Balaguer, fue un alto burócrata durante la dictadura de Trujillo, en cuyos gobiernos se curtió como político. Bajo las órdenes del tirano se posicionó como "uno de los intelectuales de mayor relieve de la dictadura" (Cassá, 2001, p. 117); ocupó importantes cargos y realizó misiones de primer orden dentro y fuera del país, llegando a desempeñar la posición de presidente. Un presidente títere, desde luego, pero es indudable que el cargo tenía suficiente relevancia como para situar a quien lo ejerciera dentro del más selecto círculo político y social.

Como su prototipo humano, el personaje es un político enigmático, parco en el hablar, solitario, metódico en sus actos, modesto en el decorado de los espacios físicos que ocupa y amante de colec- cionar objetos que le recuerden sus estadías en suelos extraños. Es muy sensible a las críticas. Por otra parte, se destaca su:

[...] agradable voz de rapsoda, de hombre sabedor de literatura, de conocedor de las divisiones de la métrica, y de las intensidades del verso; esa agradable voz que culminaba las cesuras en ascensión melódica para retomar los descensos como un galope de ritmos (Castillo, 1996, p. 204).

Como vemos, el narrador no escatima detalles para revelar la compleja naturaleza de aquel ser gastado por los años, que tenía en sus manos el control inmediato de los destinos del país. Llama la atención que un ser con las características descritas en las líneas anteriores (tan acordes al perfil poético) fuera el mismo que había encabezado (y que aún dirigía) gobiernos profundamente represivos, intolerantes y arbitrarios frente al más leve asomo de disidencia. Gobiernos que pasaron a la historia manchados de sangre criminal ${ }^{4}$. En coherencia con ese rasgo de intolerancia del anciano, desde el momento en que Larancuent fue contratado por un tal Vasallo (apelativo que subraya la clase de lealtad que exigía el caudillo a sus subalternos), recibió la advertencia de que "el doctor era caprichoso, sinuoso, en las noticias y, más que nada, incrédulo con los periodistas y los periódicos (Castillo, 1996, p. 204). En conclusión, un personaje que desconfiaba de todo y de todos, y que solo creía lo que él decidía creer.

\footnotetext{
${ }^{4}$ Ana Belén Benito Sánchez (2014) describe al Balaguer político en los siguientes términos: "El liderazgo de Joaquín Balaguer ejemplifica el prototipo de caciquismo tradicional y el dominio de la vida política a través del entramado de relaciones sociales. Este padre de los desposeídos, conservador, paternalista, tradicionalista, autoritario, sagaz en el arte de comprar lealtades y controlar votos, definió e influyó en la política nacional durante más de cuatro décadas. El viejo caudillo contaba con una red de caciques provinciales leales a los que concedía el disfrute selectivo de bienes públicos y privados. Su resistencia a ceder el control de la maquinaria reformista lo mantuvo apegado al poder a pesar de su ceguera y avanzada edad. El viejo caudillo no admitía competencia y las aspiraciones de los posibles delfines fueron castigadas con la expulsión, la salida voluntaria o la retirada del apoyo en las urnas" (p. 547).
} 
Pronto tuvo Larancuent evidencias de lo que le había advertido su contratante. Bastó un breve y trivial comentario, y que en ese comentario dejara entrever una vaga idea de insatisfacción social deducida de la apariencia que percibía en la gente que transitaba por los alrededores del entorno presidencial (que bien podía tomarse como una muestra de un sentimiento común en la población en general), para que de inmediato se viera encarado por el oidor. Sometido a un asedio interrogativo que le forzaba a revelar cualquier posible indicio de disidencia, el leedor acabó dando rienda suelta a su lengua, más allá de lo que aconsejaba la sensatez, y esa fue su ruina, lo que le llevó a perder el privilegiado puesto de leedor

Lo realmente embarazoso ocurrió cuando el leedor expresó al mandatario que a él lo engañaban, que se aprovechaban de sus limitaciones visuales para mentirle y hasta hacerle firmar documentos que no estaban destinados a los fines previstos. Aquí podría aplicarse la máxima de que "uno es amo de lo que calla y esclavo de lo que habla", y que también podría resumirse en otro dicho, más criollo y populachero: "en boca callada no entra mosca”. El hablar más de lo debido de algún modo compromete. Y Larancuent quedó comprometido con lo que habló ese día.

Esa acción dejó bastante claro que al anciano no le interesaba ningún tipo de información que pusiera en cuestión el accionar de sus burócratas. Prefería ignorar tales comportamientos y seguir actuando como si no existieran. De esa voluntad de sesgo nacía su animadversión a la prensa y a los periodistas, especialmente aquellos que hacían un periodismo crítico.

Los gobiernos autócratas, tan comunes en nuestra historia republicana, ven en todo crítico un peligroso disidente, un conspirador encubierto al que habría que atraer o deshacerse de él al precio que fuere necesario. A esa clase de autócratas pertenecía Balaguer. Su vocación tiránica no era menor que la de Trujillo, solo que las circunstancias habían cambiado y que el líder reformista era más ilustrado, por lo que controlaba mejor sus impulsos, algo que resultó siempre muy difícil para Trujillo y las demás figuras del autoritarismo político, ya que, en su mayoría (Santana, Báez, Cáceres, Heureaux...), provenían de las rudas filas militares o de las guerras montoneras del tiempo de Concho Primo. El sociólogo Wilfredo Lozano (1996) observa en el caudillo reformista una personalidad doble, cuyas partes se complementan, pero que a veces podían resultar conflictivas:

De un lado, el reformador, el estadista capaz de llegar a compromisos realistas que aseguren la continuidad y estabilidad del Estado. Del otro, el caudillo autoritario que se resiste a la modernidad, y a quien le resulta difícil asumir la incertidumbre del juego democrático (pp. 29-30).

Otras actitudes propias del gobernante que están presentes en el cuento son su desmesurado interés por la construcción de viviendas y su tendencia a las dádivas. No olvidemos que esta última práctica era una de las formas que utilizaba para rendir a sus opositores. Balaguer era pródigo en el halago y generoso en la repartición de recursos o de cuotas de poder, como medio de captación de adeptos. Y si esos medios no funcionaban para atraer o neutralizar a sus oponentes, podía recurrir al uso de la fuerza, de cuyo accionar sobran ejemplos. Ese uso arbitrario de la fuerza pública frecuentemente se traducía en encarcelamiento, exilio o muerte. El "Padre de la Democracia" podía llegar a ser implacable con sus adversarios, y no faltó ocasión para demostrarlo.

\footnotetext{
${ }^{5}$ Durante el gobierno de Hipólito Mejía, específicamente en el año 2003, un Congreso mayoritariamente perredeísta honró al Dr. Balaguer otorgándome el título de "Padre de la Democracia Dominicana". Con esta acción sepultaban bajo un alud de olvido décadas de intransigencia y autoritarismo en que los propios auspiciadores del proyecto padecieron represiones del viejo caudillo. Esta acción fue ácidamente criticada por los sectores liberales y progresistas, y fue ampliamente debatida en los medios de comunicación.
} 
El cuento de Castillo permite ver el carácter supersticioso del Presidente. Este rasgo se hace patente cuando Larancuent en uno de sus monólogos se detiene en la habitual indumentaria del personaje: "Es su bata de la suerte, según me contó hace tiempo y nadie impediría que la use día tras día" (Castillo, 1996, p. 200). Igualmente resalta su obsesión por la puntualidad (no en vano el reloj de pared aparece como un símbolo constante en diferentes pasajes del relato).

El narrador sugiere la idea de que el oidor es descuidado y desarreglado en el vestir y en el ordenamiento del ajuar de su habitación, algo que se explica por su falta de visión: "un sillón clásico, de piel cuarteada y descolorida, situado frente a frente a la butaca que ocupaba" (Castillo, 1996, p. 200). Más que una habitación personal parece un museo de antigüedades: "los sombreros de diferentes épocas: de alas anchas, como los usados por Indiana Jones, y los de alas cortitas, como los que se ponía Gary Grant en los filmes de los años cincuenta" (Castillo, 1996, p. 200). Pintoresquismo y anacronismo conviven en forma armónica en esas colecciones del ajuar particular del Presidente, la mayoría pasadas de moda. Sin embargo, esos objetos y vestuarios típicos de otra época resaltan el buen gusto y el glamour con que ese ser físicamente disminuido, pero aún lleno de vitalidad existencial, se ataviaba en sus años de juventud, cuando dirigía o formaba parte de importantes misiones diplomáticas en diversos escenarios del ámbito político.

Pero no era solamente la pérdida de la visión, la percepción de abandono, de desarreglo, se veía acrecentada por la falta de una compañera sentimental, una esposa que se ocupara de llevar los buenos hábitos de la higiene y organización del espacio, cualidades para las que las mujeres están especialmente dotadas. $\mathrm{O}$ bien de descendientes que velaran por el aseo y el ordenamiento del hábitat presidencial. En la ficción, como en la realidad concreta del personaje histórico, Balaguer era un ser profundamente solitario.

Menos pintoresco es el otro ángulo del relato en que Castillo traza el perfil moral del viejo caudillo y que se ajusta con bastante fidelidad a la personalidad del Balaguer político que es de todos conocido. Ese Balaguer que convivía con gente que se aprovechaba de los estrechos vínculos afectivos y políticos que le unían a él para extraer pingües beneficios económicos. Durante esos últimos diez años en que ejerció el poder (1986-1996) ocurrieron muchos hechos escandalosos, que nunca fueron debidamente sancionados, pues el régimen siempre tuvo el control absoluto del Poder Judicial, y nunca permitió que ninguno de sus funcionarios fuera alcanzado por la vara de la justicia, vara que entre nosotros tiene muy corto alcance. Tal y como lo denuncia Larancuent en el espacio ficcional, siempre se decía que el líder colorado era engañado por sus burócratas, dadas sus limitaciones, especialmente su ceguera, pero la verdad es que él siempre convivió con un funcionariado señalado por la opinión pública como corrupto, algo que — como ya se ha dicho-nunca pareció molestarle. Tan consciente estuvo de ello que llegó a admitir que la corrupción solo se detenía "a la puerta de su despacho". Como señala un analista de nuestra historia reciente, durante los gobiernos balagueristas siempre hubo "una percepción de corrupción estatal, sin que se lograra desarrollar ninguna política consistente en superar los estilos neopatrimoniales de ejercicio del poder en el país" (Artiles, 2019, p. 2).

Es ese el Balaguer que aparece encarnado en $E l$ oidor, ese hombre enigmático, de apariencia casi inmutable, recogido siempre en su silencio y su parquedad expresiva; pero que estimulado por una crítica o lo que él podía tomar como un indicio de desaprobación podía reaccionar de un modo colérico y desafiante. El gobernante que conocía la naturaleza aviesa de sus burócratas y que nada hacía para castigar el dolo y los abusos de aquellos. El que simulaba dejarse engañar por sus subalternos, al asumir la 
filosofía del laissez faire, laissez passer. El líder político que bien pudo engañar a muchos de los que se cruzaron con él en su dilatada carrera política, pero que no pudo ni podrá burlarse del inapelable juicio de la historia, y del que la buena literatura da cuenta.

\section{Los personajes}

En este cuento solo hay dos personajes principales: el oidor y el leedor que es identificado como Jaime Larancuent. Del oidor solo se conocen sus palabras, sus gestos y su extraño comportamiento, en los que deja traslucir más o menos sus emociones; pero como se trata de un ser enigmático, introvertido y discreto en grado sumo, no es mucho lo que se puede intuir, debido a sus habituales reservas. Es decir, es poco lo que se puede percibir de su mundo interior.

De Larancuent sabemos mucho más, ya que es el focalizador del relato, por lo que conocemos sus más íntimos pensamientos y sus más recónditas emociones. No es él quien ejerce la función de narrador, pero la instancia narrativa se vale de él para ir presentando las observaciones y evaluaciones que va procesando en sus interacciones con su interlocutor. De todos modos, él no es el personaje principal; su relevancia radica en que él funge de mediador, a través del cual nos acercamos al oidor.

Dadas las posiciones que asumen en la historia, entre estos dos personajes se produce una clara oposición. Y no solo se trata de la dicotomía entre las funciones que representan en tanto leedor $y$ oidor, sino que se da un contraste entre la situación personal del anciano presidente y la del ciudadano que descodifica signos para aquel. Dicho contraste se manifiesta de manera reiterada en la imposibilidad de ver del personaje principal frente al otro personaje que al ejercer la función de focalizador se comporta como un observador pertinaz, atento a los más nimios detalles que le rodean.
Así, el leedor Larancuent desempeña su rol gracias a que puede ejercer plenamente la facultad de ver, mientras el oidor está en una condición diametralmente opuesta. A medida que avanza el relato, el narrador en tercera persona va enfatizando esa capacidad visual del leedor al usar verbos relacionados con el sentido de la vista: "Larancuent echó un vistazo rápido a la habitación [...] Observó la ventana [...] "Vio nuevas cassettes" (Castillo, 1996, p. 199); "miró a su alrededor e intrigado le dijo..." (Castillo, 1996, p. 201). En tanto que la ceguera del oidor, parece compensarse con una gran habilidad auditiva. Esta gran sensibilidad auditiva aparece acentuada por la imagen del reloj de pared que anuncia sonoramente el cambio de hora: "(...) mientras el reloj parlador marcaba un tiempo" (Castillo, 1996, p. 202). Hay otros pasajes en que se remarca la gran capacidad auditiva del oidor. Al respecto, Larancuent pensaba que este "podía ver a través de sus oídos” (Castillo, 1996, p. 205). Esta agudeza del sentido del oído queda evidenciada en la capacidad de distinguir la más mínima variación en la voz (intensidad, tono y timbre) de quienes le leen.

Aparte de la dualidad formada por oidor y leedor, hay otro personaje en el cuento: es el General, solo identificado por su rango militar, pero que, como ya señalamos más arriba, el lector enterado relacionará de inmediato con el general Pérez Bello, ayudante militar del mandatario. Es un personaje de bajo perfil, pues de él solo aparecen algunas referencias; es casi tan enigmático como el caudillo al que sirve. "El grito provenía de la habitación vecina y el General lo miró con impaciencia dejando, casi transparente, una sonrisita entre amarga y simpática" (Castillo, 1996, p. 199). El narrador se ocupa del General en otras tres oportunidades, al inicio del relato, primer párrafo (solo se menciona, no actúa) y en dos escenas más, ambas próximas al final del relato. La penúltima, para preguntar si ya el leedor se iba a retirar, y al final cuando recibe la instrucción del oidor de que suspendieran los servicios de dicho leedor. 


\section{Procedimientos narrativos}

El narrador de El oidor es heterodiegético, ya que narra desde fuera de la diégesis. No obstante, se trata de un narrador mediatizado que, aunque está en tercera persona, renuncia a la omnisciencia absoluta como también a la objetividad para instalar su punto de mira en la conciencia de uno de los dos personajes principales: el leedor Larancuent. Así, el narrador penetra de manera exclusiva en la conciencia de ese personaje para mostrarnos sus pensamientos, percepciones, estados de ánimo, dudas..., y a los demás los muestra en su aspecto exterior y en las reacciones que evidencian y que son expresiones de sus estados interiores.

El relato transcurre de un modo casi lineal. Sin grandes saltos en sus secuencias que rompan esa linealidad temporal. Una vez inicia el acto narrativo, con la autorización que recibe el leedor (Larancuent) para entrar al despacho del oidor, el relato sigue un curso indetenible, sin rodeos ni digresiones, excepto una breve evocación infantil que no alcanza a torcer el hilo narrativo en su desplazamiento hacia el desenlace definitivo. La evocación en cuestión solo produce una distracción momentánea cuando el leedor rememora una escena de su niñez. Se trata de una breve analepsis.

\section{Elementos simbólicos}

Hay algo en El oidor que a primera lectura podría asumirse como un elemento casual, pero como bien sabemos, en literatura no puede tomarse ningún recurso expresivo como producto del azar. Sobre todo, cuando se trata de un narrador experimentado, como es el caso de Castillo. Consiste en la oposición entre dos elementos naturales: los flamboyanes rojos que estaban "encendidos" y que "parecen fuegos rojos, fuegos intensos" (Castillo, 1996, p. 202) y "las nubes blancas" (Castillo, 1996 , p. 2). Téngase en cuenta que esos colores (rojo y blanco) representaban en el espectro polí- tico de entonces dos fuerzas políticas antagónicas, que eran las más importantes en esos años: el gobernante Partido Reformista y el opositor Partido Revolucionario Dominicano. El partido rojo había ganado las más recientes elecciones, por lo que podía representarse con la intensidad de lo que está en plena vigencia, y el blanco que, aunque conservaba una alta preferencia del electorado, en ese momento se encontraba distante de los principales resortes del poder político. El simbolismo del cuadro se completa con la visión de unos edificios "recortados" y "alguna gente cabizbaja". Edificios recortados, lo que equivale a decir: disminuidos, incompletos, y gente cabizbaja; esto es, preocupada, angustiada, descontenta... nos transmiten, en clave simbólica, un cuadro desolado de la realidad cotidiana, que parece el resultado de los primeros elementos del cuadro: el rojo dominante y el blanco distante y etéreo.

Lo anterior no es el único simbolismo insertado en el relato: hay otra escena, a la que ya nos hemos referido, en que el leedor, de pie frente a la ventana, con el oidor a su lado, hace un breve ejercicio de retrospección (analepsis), recreando un episodio de su infancia, en Matancita, Nagua. El leedor se encontraba frente a un "río nervioso saltando sobre piedras y troncos; se estremeció con los lejanos truenos provenientes de las lomas y se contempló él mismo pequeño, desnudo, aterido en el atardecer templado" (Castillo, 1996, p. 203). Notemos cómo se corresponde la fragilidad del niño, solo e indefenso ante las fuerzas de la naturaleza, con la suavidad y mansedumbre del agua frente a la aspereza de las piedras y los troncos. Esa retrospección se produce cuando el oidor le interroga sobre el cuadro de realidad que se observa más allá de la ventana. Esta vez, el leedor, asediado por el oidor, se encuentra ante una situación de debilidad similar a la evocada de su niñez, impelido a hablar, a sabiendas de que si sobrepasa los límites del comedimiento puede acarrearse situaciones que pudieren resultar complicadas. 
Sin embargo, es interesante que nos detengamos en el paralelismo entre ambas situaciones. Eran circunstancias semejantes, producidas en contextos disímiles. Hay una idéntica debilidad frente a un poder superior. En la escena infantil el niño es llamado por la madre, que va en su auxilio para restituirlo al hogar, y él le responde con una voz que es "como una chispa incendiando el bosque" (Castillo, 1996, p. 203). La descripción de la voz que él transmutaba en su evocación en una imagen visual: una chispa en medio de las sombras, constituye una proyección de lo que representaría ese instrumento de comunicación para él, pues con los años se convertiría en unas de las voces más cotizadas dentro de la actividad radiofónica. No obstante, frente a esta nueva dificultad en su vida adulta ya no podía contar con el auxilio de su madre; tendría que arreglárselas por sí mismo para salir bien del reto que tenía ante sí, de cara a la máxima autoridad política del país que le interpelaba. ¿Podría salvarse haciendo un uso inteligente de ese maravilloso recurso del que disponía y que le había deparado tantas satisfacciones: su voz? Muy pronto tendría la oportunidad de comprobar que no bastaba contar con ese privilegiado don; que la virtud de la prudencia brilla por encima de cualquier otro talento, y su ausencia puede hacer desastrosa cualquier circunstancia humana.

\section{La figura de Balaguer en la literatura}

Balaguer, sujeto político que gravitó como ningún otro en el discurrir histórico del pasado siglo, reunió en su personalidad privada y en su perfil público unos rasgos que han resultado atractivos para algunos cultivadores de literatura. No obstante, a diferencia de lo que ha pasado con la figura de Trujillo, que ha inspirado una enorme cantidad de textos, sobre todo cuentos y novelas, Balaguer ha recibido una menor atención por parte de nuestros literatos.
Indagar en ese aspecto no forma parte del propósito del presente artículo; de ahí que nos limitemos a citar la inclusión del personaje en algunas obras de ficción. Una de ellas es la novela del peruano Mario Vargas Llosa: La fiesta del chivo, en la que se traza un retrato satíricamente demoledor del académico y funcionario de la dictadura. Sobra decir que en ese momento el futuro autócrata no mostraba ningún signo del caudillo en que se convertiría tras la muerte de dictador.

Al describir al burócrata trujillista, Vargas Llosa (2000) no disimula su intención paródica y burlesca, como podemos apreciar en este fragmento:

El hombrecito hablaba con la suavidad bondadosa de costumbre y un esbozo de sonrisa en su cara redonda, pronunciando con la perfección de un actor de radioteatro o un profesor de fonética. Trujillo lo escudriñó, tratando de desentrañar en su expresión, en la forma de su boca, en sus ojitos evasivos, el menor indicio, alguna alusión. Pese a su infinita suspicacia, no percibió nada; claro, el Presidente fantoche era un político demasiado ducho para que sus gestos lo traicionaran (p. 286).

También Junot Díaz (2008) en La breve y maravillosa vida de Oscar Wao, traza, el que pudiera considerarse más repulsivo retrato del caudillo:

Aunque no sea esencial para nuestro relato en sí, Balaguer es esencial en la historia dominicana, por lo que debemos mencionarlo, aunque preferiría cagarme en él. Los viejos sabios dicen: Todo lo que se menciona por primera vez llama a un demonio, y cuando los dominicanos del siglo xx pronunciaron en masa por primera vez la palabra libertad, el demonio que conjuraron fue Balaguer. (También es conocido como El Ladrón de las Elecciones —véanse las de 1966 en la 
RD— y El Homúnculo). En los días del trujillato, Balaguer era nada menos que uno de los subalternos más eficientes de El Jefe. Mucho se decía de su inteligencia (sin duda impresionó a El Cuatrero Fallido) y de su ascetismo (cuando violaba a las niñas, se lo guardaba). Después de la muerte de Trujillo, asumiría el control del Proyecto Domo y gobernaría el país de 1960 a 1962, de nuevo de 1966 a 1978, y otra vez de 1986 a 1996 (para esa época ya estaba ciego como un murciélago, una verdadera momia viviente). Durante su segundo mandato, conocido entre los locales como los Doce Años, desencadenó una oleada de violencia contra la izquierda dominicana, enviando a escuadrones de la muerte a eliminar a cientos de personas y alentando a millares a irse del país (p. 96).

También el escritor y catedrático Silvio Torres-Saillant (2002), una de las voces más reconocidas de la diáspora dominicana afincada en Estados Unidos, dibuja en estas líneas un perfil de Balaguer, al definirlo como "un bruto con erudición, cuyo poder político lo ayudó a usurpar por generaciones el blasón de intelectual" (p. 56).

Finalmente, otro autor que aborda la figura de Balaguer, convirtiéndolo en protagonista de su novela, es Viriato Sención (1992) en Los que falsificaron la firma de Dios ${ }^{6}$. En ella la personalidad de Balaguer es tratada de tal forma que desata una gran controversia, despertando el encono del propio caudillo, quien en ese momento fungía como Jefe de Estado. La obra obtuvo el voto favorable — unánime - del jurado para la adjudicación del Premio Nacional de Novela de 1992, pero las autoridades correspondientes desconocieron el veredicto y se negaron a otorgarle el premio, por considerar que se trataba de

\footnotetext{
${ }^{6}$ La novela salió a la luz en el año 1992 y se vendió de manera pocas veces vista en el país. ... La censura gubernamental se convirtió en su mejor promoción. El premio que le fue negado devino en el mayor aliciente para su demanda. El jurado que premió la obra estuvo compuesto por Diógenes Céspedes, Juan Tomás Tavárez K. y Roberto Marcallé Abreu...
}

una obra insidiosa, que irrespetaba al mandatario. De ella citamos este significativo pasaje en que uno de los personajes se refiere a Mario Ramos ${ }^{7}$ (nombre con el que el autor designa al Dr. Balaguer):

El doctor Mario Ramos no ama, no agradece, y aunque es capaz de los peores odios, éstos están larvados en su alma como una ponzońa al revés: no interfieren en sus objetivos políticos. Si has de acercarte a él hazlo bajo el estricto principio de la conveniencia: de la conveniencia para él, para el doctor Ramos. Sólo podrás convencerlo de algo si tu planteamiento le es útil. ¡Políticamente útil! Lo demás, le es intrascendente (p. 292).

Recientemente han surgido otros textos narrativos que tratan sobre el caudillo: la novela El niño que no tuvo un tambor, de la periodista Cornelia Margarita Torres (publicada en febrero del año 2019) y la colección de relatos titulada Memoria de la sangre, del cuentista y también periodista Luis Martín Gómez (septiembre de 2019).

\section{Conclusión}

Como hemos visto en el análisis de El oidor y en las citas transcritas de otros textos y autores, Balaguer ha sido una figura controversial dentro de la política y la literatura, un personaje que desató, y aún sigue desatando mucha pasión; repudiado por unos y amado por otros. A pesar de que él mismo fue un letrado, que cultivó con profusión y verdadera pasión varios géneros, como el ensayo literario y político, la biografía, la poesía e, incluso, la narrativa, no alcanzó un sitial tan alto, que fuera equiparable a sus grandes triunfos en la arena política, en un área del quehacer humano que le era especialmente querido. La política, que era su otra gran

\footnotetext{
${ }^{7}$ El nombre de Mario Ramos, para designar al Dr. Balaguer, es el equivalente masculino de aquella María Ramos del refrán, muy popular en nuestro medio: "la gatica de María Ramos, que tira la piedra y esconde la mano". Este refrán alude a la capacidad de simulación de la gente que comete actos perversos y tiene una gran habilidad para disimularlos.
} 
pasión, le ocupó sus mejores y más productivas horas, pero no le impidió dedicar una porción de su tiempo a la literatura creativa e interpretativa. Sin embargo - a nuestro juicio- los éxitos que alcanzó como figura política de primer orden no pudo replicarlos dentro del complejo mundo de la literatura.

En El oidor, que antecede a las otras obras literarias citadas, pues fue escrito varios años antes que aquellas, Castillo muestra un perfil muy realista del último gran caudillo dominicano. Entre los muchos méritos del autor al escribir este cuento está el haberlo creado cuando el personaje era un actor de primer orden en el degradado panorama político de entonces, pues se encontraba ejerciendo la Presidencia en lo que fue su último periplo: el período de los diez años que van de 1986 a 1996. Abordar, dentro de la vorágine y de las convulsiones políticas de esos años, una figura tan sensible y con tanta predisposición para el encono, representaba una gran osadía. Lo que sucedió cuatro años después con Viriato Sención y Los que falsificaron la firma de Dios evidencia el enorme reto que implicaba abordar la oscura silueta del viejo zorro político.

Sin embargo, lo anterior es un mérito extraliterario, atribuible a la circunstancia personal de su creador y al momento de la escritura, no al texto en sí. En lo que respecta al cuento, es importante señalar que, según nuestro humilde parecer, hay acierto en el desenvolvimiento del relato, en los símbolos empleados, en la caracterización de los personajes y la atmósfera psicológica que les rodea (sobre todo en cuanto se refiere a la figura del oidor), en las palabras y en los silencios. Un personaje tan complejo como el representado por el oidor hay que saber comprenderlo e interpretarlo, tanto cuando habla como cuando calla, así como en sus gestos y movimientos. El cuento no decepciona en ninguno de esos aspectos. Cada uno de los méritos que hemos destacado hacen de El oidor, de Efraím Castillo, uno de los cuentos más relevantes de la cuentística dominicana.

\section{Referencias}

Artiles, L. (2019). Los Diez Años de Gobierno del Dr. Joaquin Balaguer, 1986-1996: la dialéctica entre la inercia y la transformación del modelo de dominación social y politica de la República Dominicana. Recuperado de https://www. academia.edu/40084598/Los_Diez_Años_ de_Gobierno_del_Dr.Balaguer

Benito, A. (2014). Caciques y facciones en República Dominicana. Revista Mexicana de Sociología 76(4), 529-556.

Cassá, R. (2001). Algunos componentes del legado de Trujillo. Iberoamericana. América LatinaEspaña-Portugal, 1(3), 113-127.

Castillo, E. (1996). El oidor. En D. Céspedes (coord.). Antología del cuento dominicano. Santo Domingo: Editora de Colores.

Castillo, E. (1998). Los lectores del Ático. Santo Domingo: Editora Taller.

Céspedes, R. (24 de noviembre de 2015). 19861996. Regreso del balaguerismo (IV). Acento Digital. Recuperado de https://acento.com. do/opinion/1986-1990-regreso-del-balaguerismo-iv-8301737.html

Díaz, J. (2008). La breve y maravillosa vida de Óscar Wao. Nueva York: Vintage Español, Random House.

Espinal, R. (1992). Joaquín Balaguer. El eterno retorno de la política dominicana. Nueva Sociedad, (118), 109-115.

Lozano, W. (1996). Tradición caudillista y cambio político en República Dominicana: 1966-1994. Perfiles latinoamericanos: revista de la Facultad Latinoamericana de Ciencias Sociales, 5(8), 29-50.

Rodríguez, N. (2004). El rasero de la raza en la ensayística dominicana. Revista Iberoamericana, LXX(207), 473-490.

Sención, V. (1992). Los que falsificaron la firma de Dios. Santo Domingo: Editora Taller.

Torres, C. M. (2019). El niño que no tuvo un tambor. Santo Domingo. 
Torres-Saillant, S. (2002). Eltigueraje intelectual. Santo Domingo: Centro de Información Afroamericano /Sociedad Editorial Dominicana.
Vargas Llosa, M. (2000). La fiesta del chivo. México, D.F.: Santillana, Punto de Lectura.

\section{Datos de filiación}

Patricio García Polanco. Es Licenciado en Educación. Mención Letras Modernas por la Universidad Tecnológica de Santiago (UTESA) y Maestría en Enseñanza del Español por la Universidad de Alcalá de Henares. Es graduado del Doctorado en Espańol Lingüística y Literatura de la Pontificia Universidad Católica Madre y Maestra (PUCMM). Su línea de investigación es la Literatura Latinoamericana. 